\title{
Flexible semi-amorphous carbon nitride films with outstanding electrochemical stability derived from soluble polymeric precursors
}

\author{
Oleg Dubov ${ }^{1}$ (D), Jaume Giralt Marcé ${ }^{1}$, Agusti Fortuny ${ }^{2}$, Azael Fabregat ${ }^{1}$, Frank Stüber ${ }^{1}$, and \\ Josep Font ${ }^{1, *}$ (1) \\ ${ }^{1}$ Departament d'Enginyeria Química, Universitat Rovira I Virgili, Av. Països Catalans 26, 43007 Tarragona, Catalunya, Spain \\ ${ }^{2}$ Departament d'Enginyeria Química, Universitat Politècnica de Catalunya, EUPVG, Av. Víctor Balaguer, $s / n$, \\ 08800 Vilanova i la Geltrú, Catalunya, Spain
}

Received: 6 September 2021

Accepted: 10 January 2022

Published online:

17 February 2022

(C) The Author(s) 2022

\begin{abstract}
Uniform flexible carbon nitride coatings have been synthesized by means of annealing of films, fabricated from soluble triazine-based polymeric precursors. The coatings exhibit fascinating electrochemical stability and drastically increase the capacitance of coated carbon cloth electrodes. Following the analogue with turbostratic carbons, typically produced by means of polymeric precursors pyrolysis, we demonstrate that annealing of dried nitrogen-rich polymeric films results in coatings, composed by nearly equal atomic quantities of carbon and nitrogen, according to elemental analysis, and exhibiting noticeable mechanical robustness. X-ray difffraction patterns and infrared spectra of the materials allow to characterize them as partially amorphous carbon nitride with presumably heptazinic structure. Annealed films exhibit extrinsic semiconducting behavior with optical bandgaps in the range from 1.71 to $1.99 \mathrm{eV}$ and fairly good conductivity. The outstanding long-term electrochemical stability of annealed films makes them competitive with pyrolytic carbon, while much lower annealing temperatures allow preparation of nanocomposites with various particles. The precursor polymers were obtained by self-condensation of 2-amino-4,6-dichloro-1,3,5-triazine and condensation of cyanuric chloride with 5-aminotetrazole and 3-amino-1,2,4-triazole-5-carboxylic acid, respectively, in $\mathrm{N}, \mathrm{N}$-dimethylacetamide. The polymers contain mainly $\mathrm{C}-\mathrm{N}$ skeletal bonds and can therefore be viewed as "extension" of typical carbon nitride precursors, like melamine or dicyandiamide, to polymeric structure.
\end{abstract}

Handling Editor: Chris Cornelius.

Address correspondence to E-mail: jose.font@urv.cat

E-mail Addresses: o.v.dubov@gmail.com; agustin.fortuny@upc.edu 


\section{Introduction}

Nitrides of carbon represent a family of materials, which includes two layered analogues of graphite with layers consisted of sheets of (poly(tri-s-heptazine imide) and 1,3,5-triazine imide, respectively, as well as different products of incomplete condensation with pending amino groups [1] and, more recently, linear [2] and two-dimensional [3] triazine imides.

Carbon nitrides have become a hotspot in the materials science in the recent years due to a wealth of attractive properties that they possess. Both heptazine-based and 1,3,5-triazine-based structures exhibit fascinating thermal endurance, superior stability against oxidation and hydrolysis, biocompatibility and semiconducting properties with moderate and easily tunable bandgaps, corresponding to excitation with near UV or even blue-violet light, which makes them undoubtedly interesting for photoelectronics and photocatalysis [4].

Bulk heptazine-based graphitic carbon nitride is typically synthesized by simply pyrolyzing (even often without a need for inert atmosphere) of nitrogen-rich precursors-most typically, melamine, dicyandiamide, urea or their mixtures [1]. However, in a great number of implementations, including virtually all the electrochemical applications as well as uses for electronics and photocatalysis, it is prerequisite to deposit the material on a support, forming a film.

Many film deposition techniques, e.g., growing a film from a precursor melt or molten salt with a precursor [5, 6], vacuum sputtering [7], chemical vapor deposition (CVD) [8], electrolysis of soluble precursors using the support as an anode [2], have been successfully used and provided the production of smooth and well-ordered films.

Nonetheless, from the viewpoint of equipment simplicity, industrial feasibility and process cost, solution or suspension-based approaches are always preferred. Suspensions of carbon nitrides are well known. Following the analogue (albeit very imperfect from the structural viewpoint) of graphitic carbon nitride with graphite, chemical or ultrasonic exfoliation are typically used with the objection of obtaining a suspension of graphene-like carbon nitrides nanosheets in a solvent. The suspension is subsequently deposited on the chosen support by one of the standard liquid coating techniques (e.g., dropcasting, spincoating, dipcoating, doctor blade, spraying and still others).

However, no industrially feasible technique for exfoliation of graphitic carbon nitride have been proposed so far. Ultrasonic exfoliation in water and organic solvents typically requires tens of hours of sonication. Furthermore, the concentrations of exfoliated nanosheets are generally very low (in the order of few grams per liter) $[9,10]$.

Another possible approach to liquid coating techniques implies the use of soluble precursors. Although melamine is well known to be very poorly soluble in all common solvents, other popular precursors for carbon nitride, dicyandiamide and urea, can easily be dissolved in both water and organic solvents.

Howbeit, according to our observations and quite expectably, the low molecular weight of these compounds leads to their crystallization during solvent evaporation after the composition is applied and, similarly as with coatings derived from nanoparticles, to formation of carbon nitride particles weakly bound to the support instead of forming a smooth film. Hence, an ideal hypothetical carbon nitride film precursor should be a polymer or supramolecular complex that could form a gel upon evaporation of the solvent.

Intriguingly, the approach to synthesis of carbon nitride materials, starting from reactions of precursors in a solvent is well known, but these condensation reactions typically result in formation of nonsoluble, crosslinked products, which are further crosslinked by annealing.

For instance, in the work by Ok-Hee Kim et al. [11], carbon nitride material has been synthesized by the condensation of melamine and cyanuric chloride in $\mathrm{N}, \mathrm{N}$-dimethylformamide; $\mathrm{Xu}$ et al. [5] used as precursor a supramolecular complex of cyanuric chloride with 2,4-diamino-6-phenyl-1,3,5-tiazine (benzoguanamine). However, to the best of our knowledge no solution-based approaches allowing obtaining mechanically robust carbon nitride coatings have been proposed to date.

On the other hand, this approach does exist and is well developed for carbon-based materials without a substantial nitrogen content. Partially ordered forms of carbon with folded graphitic nano-ribbons, erroneously called "glassy carbon" or, more precisely, pyrolytic carbon, are known from mid-1950s [12, 13]. 
These materials have emerged into a golden standard in electrochemical measurements, being exceptionally stable in both anodic and cathodic polarization regimes and showing no own catalytic activity.

Pyrolitic carbons are typically synthesized by pyrolysis of crosslinked polymeric precursors, more often phenol-formaldehyde resins. By pyrolizing crosslinked polymer films deposited on carbon or ceramic substrates, pyrolitic carbon coatings can be obtained.

Pyrolitic materials with some nitrogen content, obtained from polymers, are also well known, although to our knowledge none of them has been reported to have fraction of nitrogen even near to that of graphitic carbon nitride (57.1 at\%) and their poor long-term electrochemical stability has recently been reported and related with typically low graphitic nitrogen content in these materials [14].

Although pyrolytic carbons are unique electrochemical materials due to their electrochemical inertness and possibility to produce electrodes with complex shapes [13], there are three inherent properties of these materials that complicate their use in many practical fields. High elastic modulus and brittleness impede fabrication of thin films and filaments, eminent hydrophobicity results in poor wetting of electrodes in water-based systems, while high fabrication temperature leads to practical unfeasibility of functional composites production that would involve pyrolysis of polymeric precursors of glassy carbon with catalytically active complexes or nanoparticles.

According to our findings, all these issues can be simultaneously addressed by incorporation of high amounts of nitrogen into pyrolytic carbon matrix.

In this work, we report the synthesis of three soluble polymers, one of which is completely triazine-based and other two represent block polyimides of triazine with nitrogen-rich heterocyclic amines. Pyrolysis of dried polymer films results in the materials with high nitrogen content, low density, exceptional stability to oxidation and reduction and XRD and AFM patterns closely resembling pyrolytic carbons.

\section{Experimental section}

\section{Materials and methods}

All chemicals have been purchased from Sigma Aldrich and used without any additional purification. Anhydrous $99.8 \%$ pure N,N-dimethylacetamide (DMAc) (Sigma Aldrich), $<0.005 \%$ water, has been used as a solvent in all polymer syntheses. $3.18 \mathrm{~mm}$ thick, carbon cloth (CC) sheets and glassy carbon plates for electrodes fabrication have been purchased from Alfa Aesar.

2-amino-4,6-dichloro-1,3,5-triazine was obtained from cyanuric chloride by ammonolysis in acetonewater solution according to the procedure described by Baliani et al. in the Supporting Information provided for their publication [15]. 5-aminotetrazole was obtained by drying the corresponding monohydrate (purchased from Sigma Aldrich) in air at $105{ }^{\circ} \mathrm{C}$ for $24 \mathrm{~h}$ according to the procedure described in [16], followed by keeping the product two weeks in vacuum desiccator over $\mathrm{P}_{2} \mathrm{O}_{5}$.

NMR spectra have been recorded using a VARIAN Mercury VX400 spectrometer.

SEC chromatography installation consisted of an Agilent 1260 Isocratic Pump, manual sample injector Rheodyne Model 7125 with $20 \mathrm{~mL}$ loop, two PLgel $5 \mathrm{~mm}$ Mixed-D $30 \times 7.5 \mathrm{~mm}$ linear columns (MW 200-400.000) 75,970 and 97,293 plates/m (1/2 ht)) with an Agilent 1100 series refractive index detector.

JASCO 4700 spectrometer has been used for FTIR spectra recording. Infrared spectra have been processed in free SpectraGryph software.

Thermogravimetric analysis has been carried out with SETARAM SENSYS EVO 3D Tech. For analysis, sample (of around $10 \mathrm{mg}$ ) was placed in platinum pan and heated at a constant rate of $4{ }^{\circ} \mathrm{C} / \mathrm{min}$.

Elemental analysis of the samples was performed using Perkin Elmer EA2400 serie II elemental analyzer after sample incineration at $930^{\circ} \mathrm{C}$.

UV-Vis diffuse reflectance spectroscopy measurements were carried out using a Shimadzu UV-3600 equipment with $\mathrm{BaSO}_{4}$-coated integration sphere.

JEOL model 1011 and Thermo Fisher SCIOS 2 with field emitter have been used for transmission and scanning electronic microscopy/EDX, respectively.

STM scanning has been performed on Pico SPM II $($ Pico +$)$ system.

XRD (X-ray diffraction) measurements were made using a Siemens D5000 diffractometer (Bragg-Brentano parafocusing geometry and vertical $\theta-\theta$ goniometer) fitted with a curved graphite diffractedbeam monochromator, incident and diffracted beam Soller slits, a $0.06^{\circ}$ receiving slit and scintillation counter as a detector. 
Contact angles have been measured by the static sessile drop method using Kyowa Interface Science DM211 goniometer for films.

Autolab PGSTAT204 with FRA32M has been used for all electrochemical experiments. Free EIS Spectrum Analyzer software has been used for profile fitting.

\section{Polymer precursors synthesis and characterization}

Three nitrogen-rich triazine-based polymers have been synthesized by self-condensation and condensation reactions, respectively. $\mathrm{N}, \mathrm{N}$-dimethylacetamide (DMAc) has been used as a solvent and N,Ndiisopropylethylamine (DIPEA) as a non-nucleophilic base in all cases (Fig. 1). Sodium and potassium carbonates were also tested and found to be effective acid scavengers for these syntheses, although their utilization derives in prominent increase of reaction suspension viscosity, which complicates the lab-scale synthesis by setting on the need for intensive mechanical stirring.

The first polymer, [azanediyl (2-chloro-1,3,5-triazine-4,6-diyl)], further abbreviated as poly(CYA-Cl$\mathrm{NH}$ ), have been synthesized by self-condensation of 2-amino-4,6-dichloro-1,3,5-triazine.

Two other polymers, poly[(2-chloro-1,3,5-triazine4,6-diyl (5-iminotetrazol-2-yl)], further abbreviated as poly(CYA-Cl-AMTAZ), and poly [(2-chloro- 1,3,5triazine-4,6-diyl (5-carboxy-3-iminotriazol-1-yl)], further abbreviated as poly(CYA-Cl-AMCARTRIA), were synthesized by condensation of 5-aminotetrazole and 3-amino-1,2,4-triazole-5-carboxylic acid, respectively, with cyanuric chloride. All the three polymers were originally obtained in the form of $5 \%$ wt. solutions in DMAc, containing also DIPEA and DIPEA.HCl.

Figure 1 Reaction schemes for the syntheses of precursors.

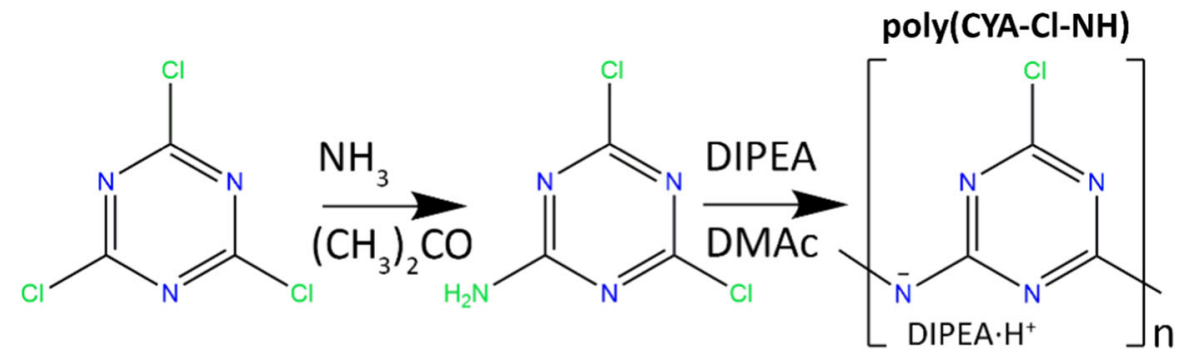

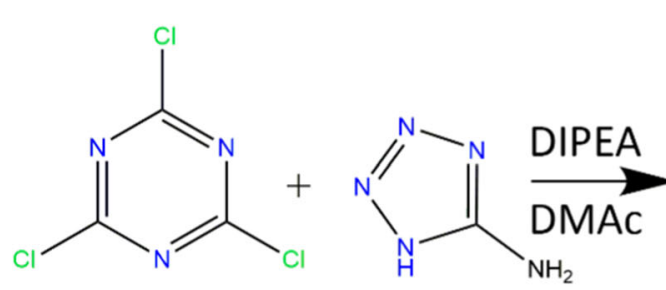

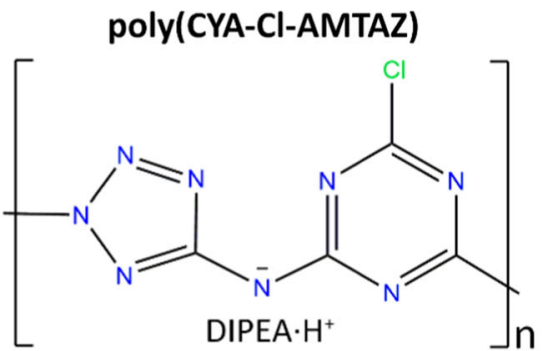<smiles>Nc1n[nH]c(C(=O)O)n1</smiles><smiles>CCn1nc(Nc2nc(Cl)nc(C3(C)CCCC3)n2)nc1C(=O)O[PH3+]</smiles> 
The detailed synthesis protocols were as follows:

\section{Synthesis of poly [azanediyl (2-chloro-1,3,5-triazine-4,6- diyl)], further abbreviated as poly (CYA-Cl-NH)}

$8 \mathrm{mmol}$ (1.32 g) of 2-amino-4,6-dichloro-1,3,5-triazine and $24 \mathrm{mmol}(3.10 \mathrm{~g})$ of $\mathrm{N}, \mathrm{N}$-diisopropylethylamine (DIPEA) were dissolved in $10.3 \mathrm{~g}$ of DMAc. The vial was purged with Ar and sealed. The solution was refluxed at room temperature for $20 \mathrm{~min}$, then heated to $110{ }^{\circ} \mathrm{C}$ and left under reflux at this temperature for $72 \mathrm{~h}$.

\section{Synthesis of poly [(2-chloro-1,3,5-triazine-4,6-diyl (5-} iminotetrazol-2-yl)], further abbreviated as poly (CYA-ClAMTAZ)

$8 \mathrm{mmol}(0.68 \mathrm{~g})$ of 5-aminotetrazole and $24 \mathrm{mmol}$ (3.10 g) of N,N-diisopropylethylamine (DIPEA) were dissolved in $20 \mathrm{~g}$ of DMAc. The solution was cooled down to $-5{ }^{\circ} \mathrm{C}$. In continuous Ar flow, a solution of $8 \mathrm{mmol}$ of cyanuric chloride $(1.48 \mathrm{~g})$ in $6.18 \mathrm{~g}$ DMAc was added to the mixture dropwise under cooling in ice $+\mathrm{NaCl}$ bath and intensive stirring so that the temperature would not have exceeded $0{ }^{\circ} \mathrm{C}$. After finishing the addition, the solution was refluxed at room temperature for $20 \mathrm{~min}$, then sealed, heated to $70{ }^{\circ} \mathrm{C}$ and left under reflux at this temperature for $24 \mathrm{~h}$.

Intensive production of heat and color change to fluorescent-yellow take place immediately after addition of the first portions of cyanuric chloride, indicating that the formation of conjugated condensation products starts instantly even at low temperatures. It is of critical importance to maintain the temperature below $0{ }^{\circ} \mathrm{C}$ during all the process of cyanuric chloride addition. At higher temperatures, an insoluble product is formed, probably as a result of cross-linking due to known noticeable reactivity of the last chlorine atom in cyanuric chloride at elevated temperatures [11].

\section{Synthesis of poly [(2-chloro-1,3,5-triazine-4,6-diyl (5- carboxy-3-iminotetriazol-1-yl)], further abbreviated as poly(CYA-Cl-AMCARTRIA)}

$8 \mathrm{mmol}$ (1.02 g) of 3-amino-1,2,4-triazole-5-carboxylic acid was suspended in $20 \mathrm{~g}$ of DMAc and $40 \mathrm{mmol}$
(5.20 g) of N,N-diisopropylethylamine (DIPEA) were added to the suspension. In continuous Ar flow, a solution of $8 \mathrm{mmol}$ of cyanuric chloride $(1.48 \mathrm{~g})$ in $10.62 \mathrm{~g}$ DMAc was added to the mixture dropwise at room temperature. In contrast with the CYA-ClAMTAZ synthesis, no color change nor heat production have been mentioned during the monomers mixing stage of the reaction towards CYA-ClAMCARTRIA, indicating much lower reactivity. For this reason, no cooling of the reaction mixture has been used. After finishing the addition, the solution was sealed, heated to $110{ }^{\circ} \mathrm{C}$ and left under reflux at this temperature for $72 \mathrm{~h}$.

NMR characterization of as-synthesized polymer solutions was performed with ${ }^{1} \mathrm{H}$ spectra of as-synthesized solutions (i.e., in non-deuterated DMAc).

Spectra (provided in the SI) of all the polymers in DMAc do not reveal any signals related to reagents (2-amino-4,6-dichloro-1,3,5-triazine and 5-aminotetrazole, respectively) neither imide hydrogens of the products. The spectra contain only peaks of DMAc, DIPEA and DIPEA.HCl. The position of neutral DIPEA signals as well as the chemical shift of ammonium hydrogen in DIPEA hydrochloride was previously established by recording a spectrum of DIPEA + DIPEA.HCl solutions in DMAc with concentrations corresponding to the expected concentration of these species in polymers solutions.

Solvent exclusion chromatography (SEC, GPC) of the polymers was carried out for as-synthesized solutions, diluted by DMF with LiBr. Table 1 summarizes the results with molecular masses, corresponding with all peaks believed to be linked with products. Numerical indexes go along with numbers of peaks, provided in the SI.

It is important to emphasize, however, that SEC experiments conducted in this study were undoubtedly affected by two inevitable issues: the standard used for calibration (PMMA) was very different from examined polymers in chain mechanics and polarity; the samples were injected "as synthesized", which resulted in impurities peaks way more intensive than polymer peaks. Consequently, the molecular weight values obtained in both SEC analyses can only be considered true by the order of magnitude. 
Table 1 Molecular masses, determined by SEC

\begin{tabular}{lllll}
\hline Polymer & $\mathrm{Mn}, \mathrm{Da}$ & $\mathrm{Mw}, \mathrm{Da}$ & $\mathrm{Mp}, \mathrm{Da}$ & $\mathrm{D}$ \\
\hline $\begin{array}{l}\text { Poly(CYA-Cl-NH) } \\
\text { (two peaks) }\end{array}$ & $1.14,460$ & $1.15,600$ & $1.14,500$ & $1.1,079$ \\
Poly(CYA-Cl-AMTAZ) & 2.5840 & 2.6130 & 2.6120 & 2.1 .048 \\
(two nearly & $1+2$ & $1+2$ & $1.84,706$ & $1+2$ \\
merging peaks) & 78,697 & 91,041 & $2.64,875$ & 1.157 \\
Poly(CYA-Cl-AMCARTRIA) & 552 & 566 & 592 & 1.025 \\
\hline
\end{tabular}

\section{Preparation of polymer precursor coatings from DMAc solutions and FTIR characterization of their annealing at different temperatures}

Application of as-synthesized solutions of all three polymers on any thermally stable support (glassy carbon, carbon cloth, $\mathrm{Al}_{2} \mathrm{O}_{3}$ ceramics plate or Ti foil have been used in our experiments) with subsequent drying at $110{ }^{\circ} \mathrm{C}$ for $24 \mathrm{~h}$ allows evaporating the solvent as well as DIPEA and its hydrochloride (ascertained by drastically reduced intensity of sharp peaks with maximums at 2920 and $2960 \mathrm{~cm}^{-1}$ in FTIR spectrum, corresponding with the absorption of DMAc and DIPEA species, as discussed below in this chapter) and obtaining smooth, welladhered films.

In order to examine the process of thermal transformation of the precursors, the films applied on glassy carbon plates were subjected to pyrolysis in Ar atmosphere. The temperature range that is practically used for pyrolytic synthesis of carbon nitride materials is well established and relatively narrow, according to all the cited literature sources $[1,3-6,8,10,11,17,18]$. When using melamine or dicyandiamide as starting materials, condensation to melem (2,5,8-triamino-heptazine) and similar oligomeric intermediates is typically believed to start at about $350{ }^{\circ} \mathrm{C}[1,19]$. Temperatures above $700{ }^{\circ} \mathrm{C}$ are commonly reported to cause decomposition of most carbon nitride materials. In our experiments, in agreement with the latter, pyrolysis at temperatures exceeding $650{ }^{\circ} \mathrm{C}$ always resulted in disappearance of coating.

In all experimental runs, the standard pyrolysis procedure started from annealing the sample at $200{ }^{\circ} \mathrm{C}$ for $1 \mathrm{~h}$, followed by ramping the temperature at $1{ }^{\circ} \mathrm{C}$ per minute to the desired temperature-300, $350,400,450,500$ or $550{ }^{\circ} \mathrm{C}$. Non-annealed films spectra were recorded after standard drying $\left(110{ }^{\circ} \mathrm{C}\right.$ for $24 \mathrm{~h}$ in air). The spectra recorded for all three precursor polymers as well as for the annealed materials derived therefrom show peculiar similarity in the position of peaks, albeit the intensity of absorption steadily decreases with increase of pyrolysis temperature (Figs. 2-4).

As can be seen from the spectra provided (Figs. 24 ), all the precursor polymers as well as films obtained by their annealing, show wide high-intensity band composed by overlapping peaks in between 1450 and $1800 \mathrm{~cm}^{-1}$, diffuse absorption region placed between 2600 and $3700 \mathrm{~cm}^{-1}$ and sharp peak around $816 \mathrm{~cm}^{-1}$. Two small sharp peaks at 2920 and $2960 \mathrm{~cm}^{-1}$, disappearing after annealing at $400{ }^{\circ} \mathrm{C}$ or above, were assigned to the remaining DMAc and DIPEA species, respectively, decomposing at high temperatures.

The DMAc and DIPEA salt characteristic peaks were acquired by preliminary recording the corresponding spectra of pure DMAc and DIPEA*HCl samples. These absorption maximums with much higher intensities appear in the spectra of films, dried at lower temperatures or lesser time.

\section{Thermogravimetric characterization of polymers annealing}

For the purpose of TGA characterization, DMAc assynthesized solutions of all three precursor polymers were placed in Petri dishes with liquid layer thickness of about $1 \mathrm{~mm}$ and dried in air at $110^{\circ} \mathrm{C}$ for 20 days in order to provide a maximum possible efficiency of DMAc and DIPEA species removal. It was previously found out in our experiments that DMAc/DIPEA/DIPEA. $\mathrm{HCl}$ solution with the ratio of components similar to that found in as-synthesized polymer solutions, completely evaporates at this temperature and in the same layer within $12 \mathrm{~h}$.

Taking into account previously mentioned disappearance of all polymeric films at annealing 
Figure 2 Infrared spectra of poly(CYA-Cl-NH) films on vitreous carbon support, annealed at different temperatures.
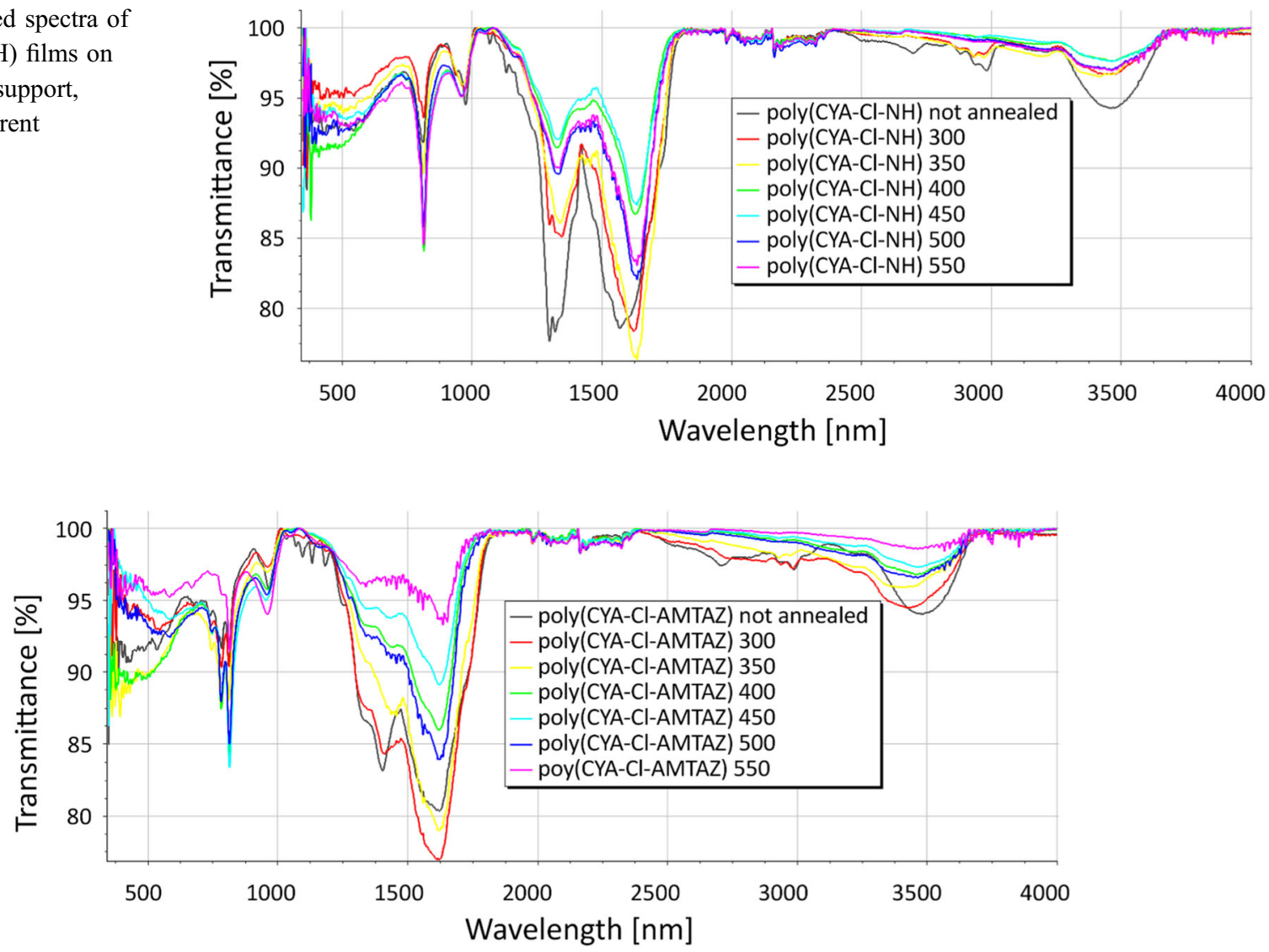

Figure 3 Infrared spectra of poly( CYA-Cl-AMTAZ) films on vitreous carbon support, annealed at different temperatures.

Figure 4 Infrared spectra of poly(CYA-Cl-AMCARTRIA) films on vitreous carbon support, annealed at different temperatures.

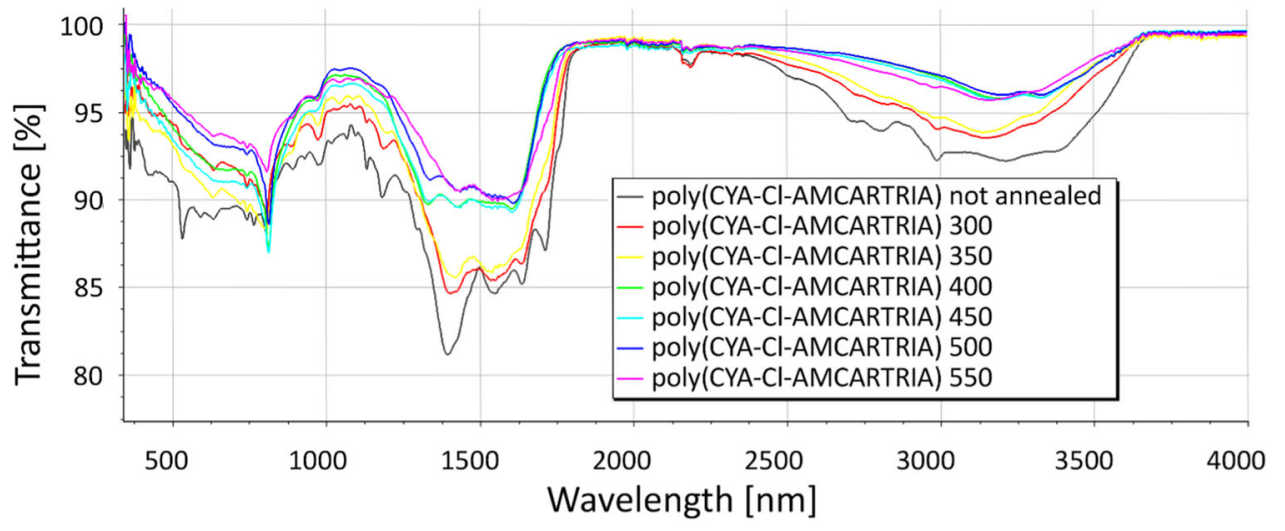

Albeit additional research is needed to explore the pathway of decomposition, it can be assumed that the pattern of mass loss in the interval from 180 to $260{ }^{\circ} \mathrm{C}$, nearly identical for all the three materials, is related to the decomposition of the polymer-bound DIPEA, i.e. DIPEA serving as counter-cation for the temperatures exceeding $650{ }^{\circ} \mathrm{C}$, we have recorded TGA in the temperature range from 70 to $700{ }^{\circ} \mathrm{C}$ (Fig. 5).

For all curves, at temperatures below $160{ }^{\circ} \mathrm{C}$, only minor depletion of mass has been observed, presumably linked to evaporation of traces of DMAc and DIPEA/DIPEA.HCl. 
Figure 5 TGA curves for the three precursor polymers.

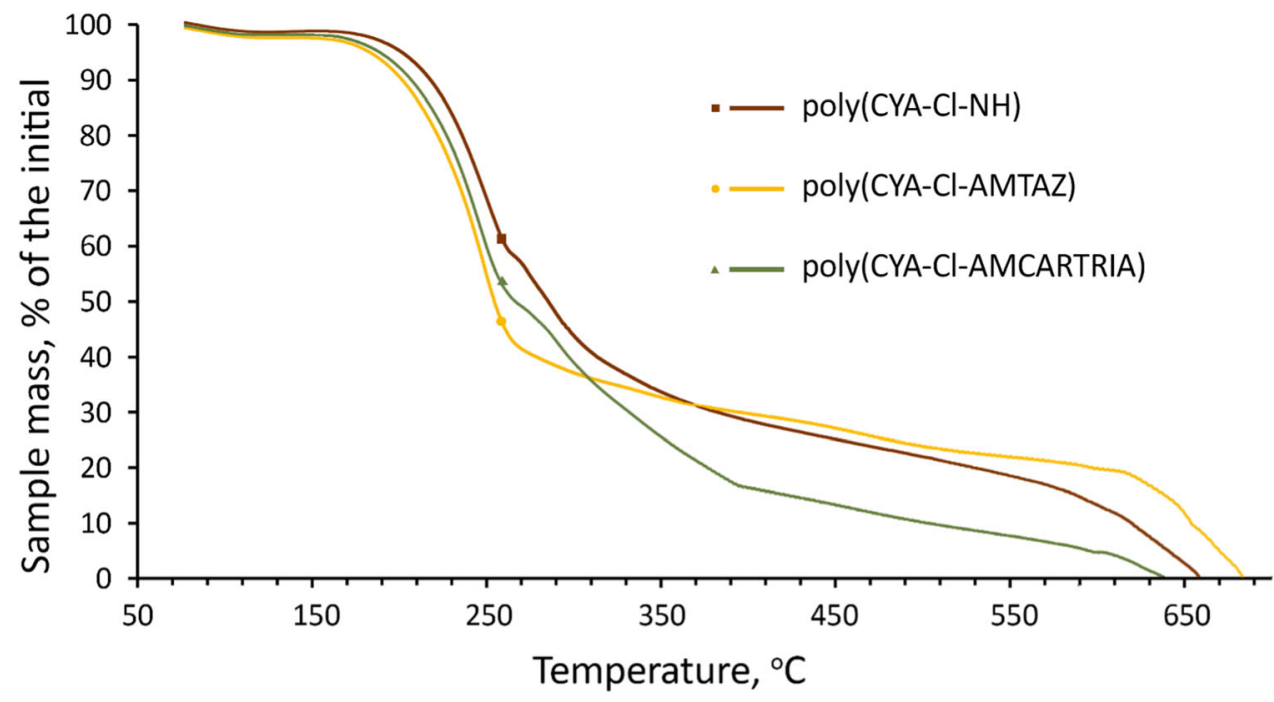

polymer and hence not sublimed in the DIPEA-HCl form during preliminary drying.

At higher temperatures, the actual transformation of polymer chains supposingly starts. Increased mass loss dynamics demonstrated by poly(CYA-ClAMCARTRIA) above $300{ }^{\circ} \mathrm{C}$ can be related to decarboxylation of the precursor.

Although it would have been logical to expect the poly(CYA-Cl-AMTAZ) precursor to exhibit comparatively quicker decomposition or/and lower onset temperature due to presence of unstable tetrazole ring, its actual mass loss curve have not demonstrated any significant differences from other polymers. It goes in line with the observation already made in the FTIR spectra analysis, supporting the assumption that tetrazole cycle stability in triazineimide-linked polymers is fairly high in comparison with monomeric tetrazole compounds.

All preliminary transformations terminate above $400{ }^{\circ} \mathrm{C}$ for all the three polymers, with subsequent process likely corresponding to steady decomposition of already formed carbon nitride product, which goes in line with minor FTIR spectra changes above this point. This process accelerates above $600{ }^{\circ} \mathrm{C}$, resulting in complete disappearance of all materials in the temperature range from 640 to $690{ }^{\circ} \mathrm{C}$.

\section{Elemental analysis}

Elemental analysis was performed on samples, prepared according to the same procedure as used for TGA. The results for mass \% contents of $\mathrm{C}, \mathrm{N}$ and $\mathrm{H}$ are provided in the Table 2.
It was expected that the remaining mass of samples to be represented mainly by chlorine and oxygen. Although the elemental analysis procedure did not allow us to determine these elements, we attempted to estimate their content using FSEM-integrated EDX spectrometry. EDX spectrometry can only be viewed as a rough semi-quantitave technique for light elements such as $\mathrm{C}, \mathrm{N}$ and $\mathrm{O}$, while typically providing more reliable results for $\mathrm{Cl}$. Although the figures were fluctuating boldly between samples, for all the measured instances of films the atomic \% contents of carbon and nitrogen, calculated in the assumption of zero hydrogen content due to inability of EDX to detect hydrogen, were in ranges 45-52 and $31-45$ at\%, respectively, thus being well in agreement with elemental analysis data.

For chlorine (also in the assumption of zero hydrogen content) the values were measured to be in the range 0.2-0.4 at\% for poly(CYA-Cl-NH) samples and $0.5-0.9$ at $\%$ for poly(CYA-Cl-AMTAZ) and poly(CYA-Cl-AMCARTRIA). Oxygen content for all the samples fluctuated in the 0.3-0.6 at\% range regardless the precursor, but increasing noticeably for samples kept in air before measurement.

Thus, it can be concluded that values, obtained in the course of EDX measurements, although lack accuracy, allow stating that all the remaining mass of the samples can be explained by presence of relatively small amounts of chlorine and oxygen. The oxygen (and hence hydrogen) contents are at least partially related to the presence of absorbed water, so measurement procedure with complete moisture protection is to be implemented for precise 
Table 2 Elemental analysis results for the synthesized polymers

\begin{tabular}{llllll}
\hline Precursor polymer & $\mathrm{C}(\mathrm{wt} \%)$ & $\mathrm{N}(\mathrm{wt} \%)$ & $\mathrm{H}(\mathrm{wt} \%)$ & Others (wt\%) & Formula \\
\hline poly(CYA-Cl-NH) & 51.40 & 47.31 & 0.71 & 0.58 & $\mathrm{CN}_{0.79} \mathrm{H}_{0.17}$ \\
poly(CYA-Cl- AMTAZ) & 48.35 & 49.26 & 0.48 & 1.91 & $\mathrm{CN}_{0.87} \mathrm{H}_{0.12}$ \\
poly(CYA-Cl-AMCARTRIA) & 54.22 & 42.12 & 2.08 & 1.58 & $\mathrm{CN}_{0.67} \mathrm{H}_{0.46}$ \\
\hline
\end{tabular}

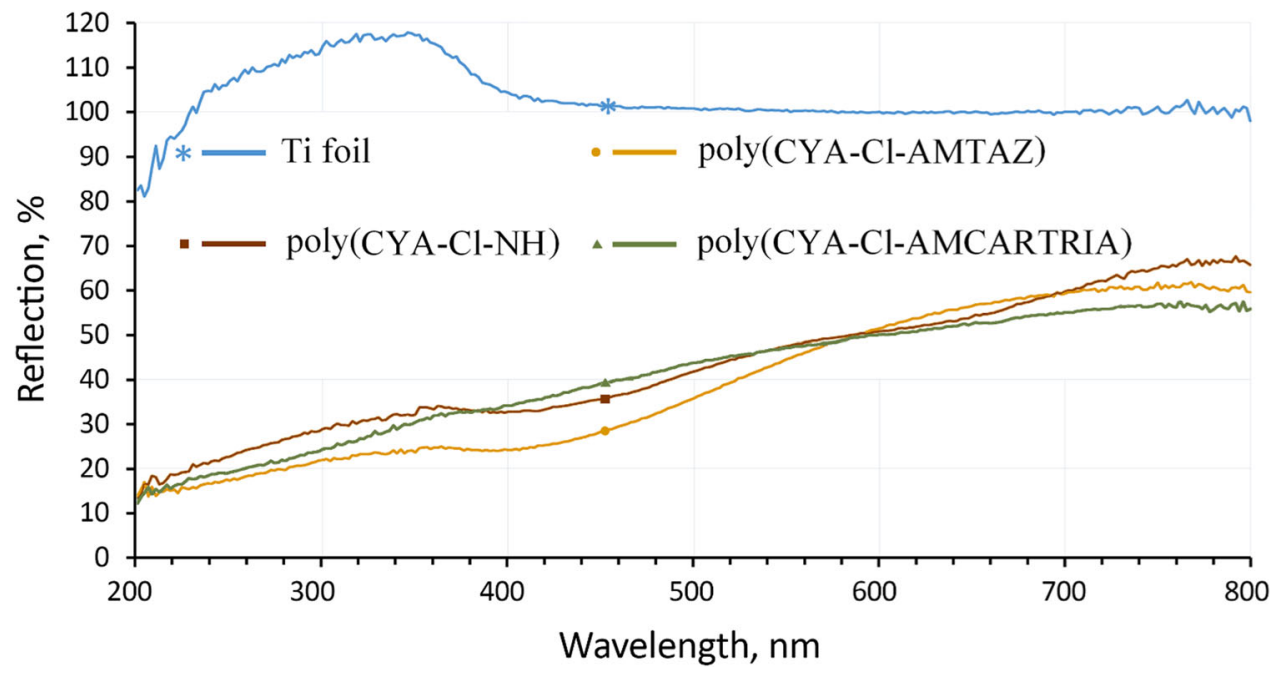

Figure 6 UV-VIS DRS for annealed coatings on $\mathrm{Ti}$ support. determination of oxygen and hydrogen. Higher apparent content of hydrogen in poly $(\mathrm{CYA}-\mathrm{Cl}-$ AMCARTRIA)-derived films is probably related to increased water absorption rate of this film.

\section{UV-Visible diffuse reflectance spectroscopy and optical bandgap determination}

Films, annealed in Ar atmosphere, derived from all three precursors on Ti foil support without secondary treatment were taken for characterization. The represented spectra are baseline-corrected, $\mathrm{BaSO}_{4}$-coated white standard plug used for recording the baseline. Pure Ti foil DRS has been determined and have shown more efficient reflection than the standard $\mathrm{BaSO}_{4}$ plug which resulted in values exceeding $100 \%$ for Ti reflection.

As can be observed in the Fig. 6, all polymers demonstrate very similar UV reflection behavior. Optical bandgaps for three polymer-derived materials were determined by outlining the corresponding Tauc plots (provided in the SI).

The optical bandgaps were calculated to be 1.88 , 1.99 and $1.71 \mathrm{eV}$ for poly(CYA-Cl-NH), poly(CYA-ClAMTAZ) and poly(CYA- Cl-AMCARTRIA), respectively. These values are way below the bandgap of graphitic and polymeric carbon nitride, typically reported to be $2.8-2.9 \mathrm{eV}[4,5]$, and correspond with visible light excitation (623 to $725 \mathrm{~nm}$ ). Hence, all the materials can be regarded as low-bandgap semiconductors.

We suppose that the reduced bandgap values are related to carbon doping of the films. It can easily be noted that the bandgap correlates with the content of nitrogen in the annealed sample, with CYA-ClAMTAZ-based sample $49.26 \% \mathrm{~N}$ wt. demonstrating the highest bandgap (1.99 eV), followed by samples based on CYA-Cl-NH with $47.31 \% \mathrm{~N}$ wt. and $1.88 \mathrm{eV}$ and, finally, on CYA-Cl-AMCARTRIA containing $42.12 \% \mathrm{~N}$ wt $\%$ and showing the lowest bandgap of $1.71 \mathrm{eV}$. For such a low bandgap range, noticeable dark conductivity can be expected.

\section{SEM, TEM and STM characterization}

SEM of all annealed films demonstrate non-informative, extremely smooth surfaces without any noticeable patterns at all available magnifications up to $100 \mathrm{~K}$. TEM of films, mechanically scratched out of Ti support, reveals their hazy structure with small nebulous clumps. No obvious distinction between films, derived from different precursors, has been mentioned. The corresponding TEM images are provided in the SI. 
Figure 7 High resolution STM images of poly(CYA-ClAMTAZ) film on Ti substrate, annealed at $550{ }^{\circ} \mathrm{C}$.
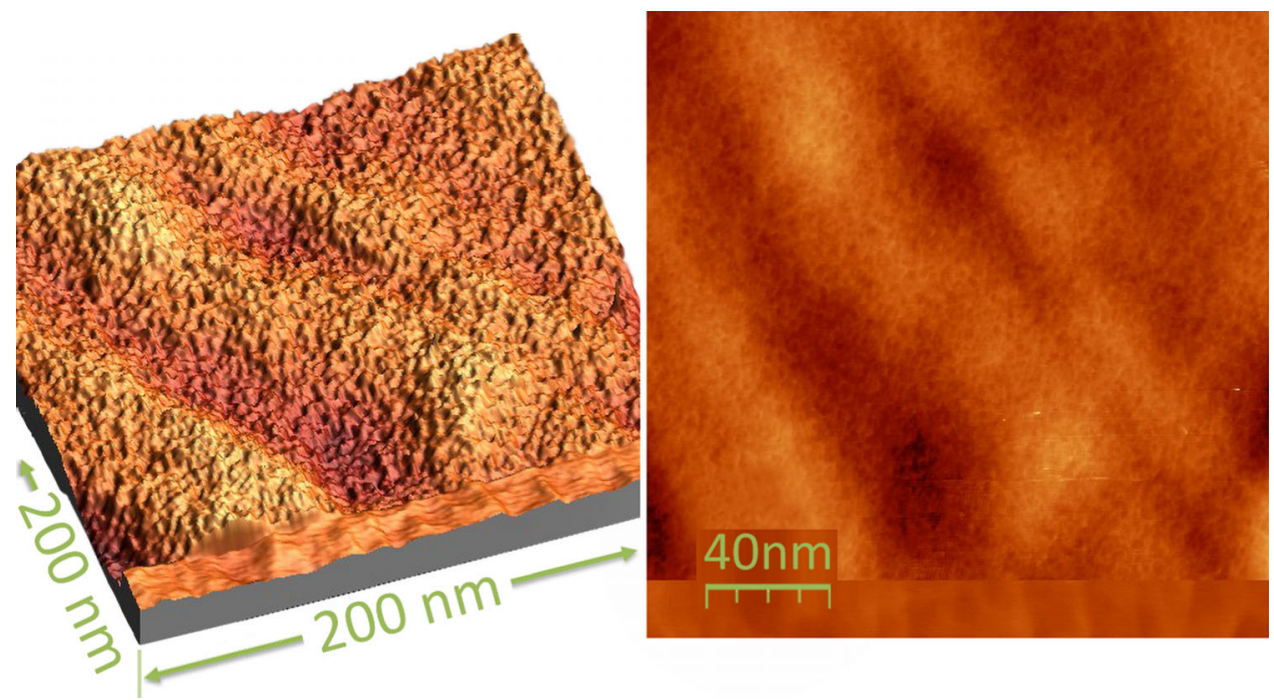

High-resolution STM microscopy (Fig. 7), carried out in non-contact mode in ambient conditions, supports the conviction that surface of all the films is smooth down to the level of hundreds nanometers. At higher magnification the FM mode scans show wave-like protrusions on the surface sized in the range of dozens of nanometers and small $(2-5 \mathrm{~nm})$ ripple, which can be related to chaotically packed protuberances of melon-like nanoribbons. STM images of glassy carbons, existing in the literature $([20,21])$, support this point of view, demonstrating similar granular, fiber-like or groove-like nanostructures on their surface, although typically of marginally larger size.

\section{XRD of annealed films and glassy carbon powder reference}

As it was previously shown in TGA experiments, drying and subsequent pyrolysis of polymeric precursors in thick layers (more than $200 \mu \mathrm{m}$ after solvent drying) implies incomplete evaporation of DMAc and DIPEA species, typically leading to altered structure and mechanical properties.

For this reason, samples for XRD characterization were prepared by means of spreading as-synthesized solutions of polymers on $100 \mu \mathrm{m}$ Ti foil with subsequent drying for $24 \mathrm{~h}$ at $110{ }^{\circ} \mathrm{C}$ and annealing in $\mathrm{Ar}$ with starting temperature of $200{ }^{\circ} \mathrm{C}$, final temperature of $550{ }^{\circ} \mathrm{C}$ and $1{ }^{\circ} \mathrm{C} / \mathrm{min}$ ramp. The resulting coating thickness was in the range from 30 to $55 \mu \mathrm{m}$ according to microscopic measurement. The annealed foils with carbon nitride coatings were then dissolved in 5\% hydrofluoric acid at room temperature, the exfoliated carbon nitride flakes washed with deionized water to neutral $\mathrm{pH}$ and dried on paper filter at $110{ }^{\circ} \mathrm{C}$ in air for $24 \mathrm{~h}$. They were grinded before XRD characterization, although due to extreme mechanical resilience of films, the shape of the resulting particles remained lamellar with 10-15 $\mu \mathrm{m}$ average diameter. Glassy carbon powder (grinded from glassy carbon rod, Alfa Aesar) was used as reference material with confirmed turbostratic structure. Further details of XRD characterization experiments and apparent crystallite sizes calculation are provided in the SI.

The X-ray diffraction patterns of all the three annealed films, given in the Fig. 8, demonstrate evident similarity, with one diffuse peak centered at $27.05^{\circ}$ and well-corresponding with characteristic (002) plane reflection of theoretically considered fully polymerized hexagonal carbon nitride, typically ascribed as arising from interlayer reflection. The absence of other relatively weak reflections, described for graphitic carbon nitride, e.g., from planes (100), (600) or (004) [22], has been related to flat shape of particles that resulted in anisotropicity of the sample.

The glassy carbon powder diffraction pattern, provided in the Fig. 9, corresponds well with previously reported results. The main peak at $23.87^{\circ}$ and lower intensity maximum at $44.14^{\circ}$ are typically found in similar positions in glassy carbon difractograms and are usually ascribed as (002) and (100) indices of graphite lattice, respectively [23]. 
Figure 8 XRD spectra of HFdetached films, annealed at $550{ }^{\circ} \mathrm{C}$.

Figure 9 XRD spectra of glassy carbon powder.
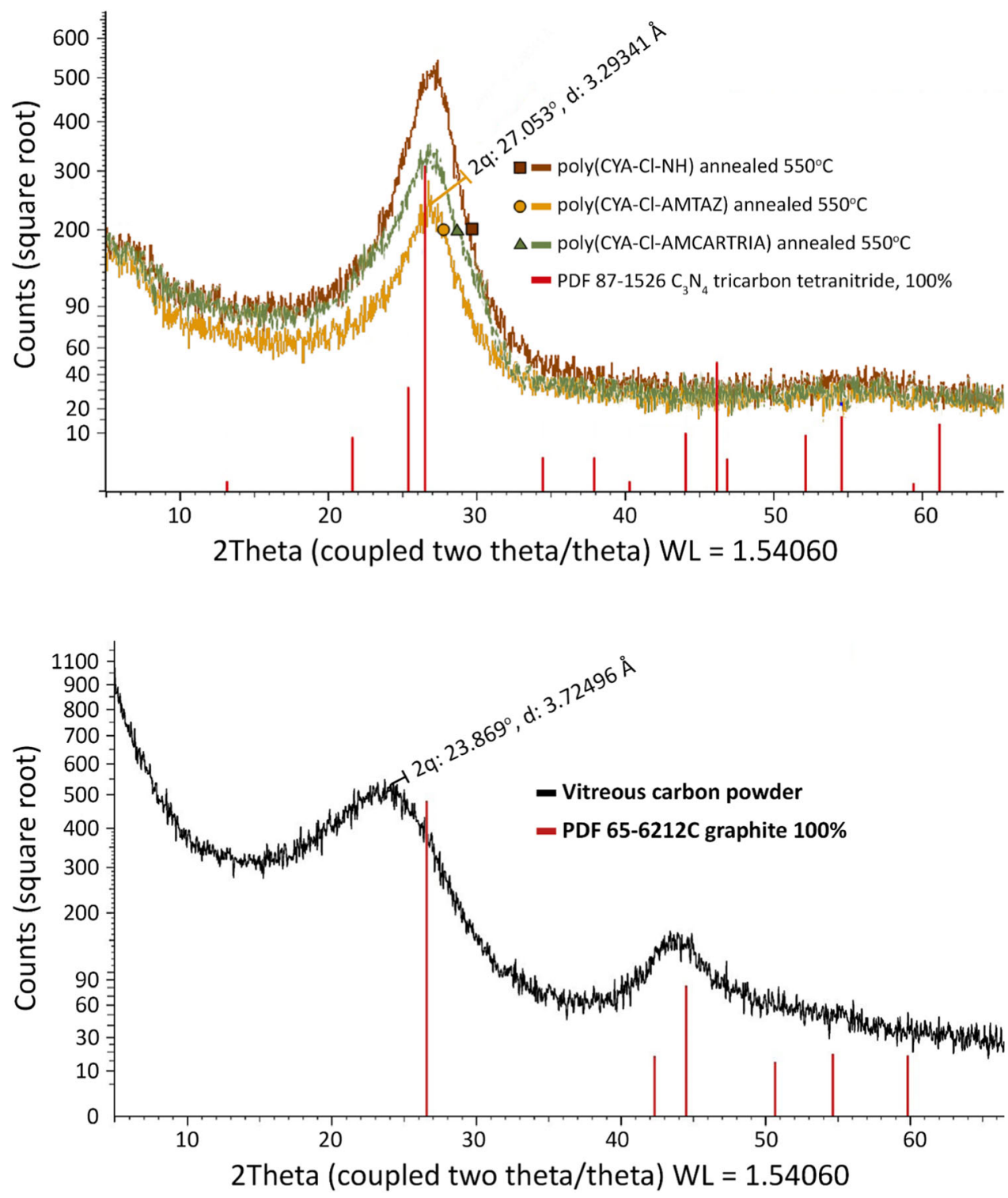

The main (002) reflections have similar shapes in both polymer-derived carbon nitride and glassy carbon samples and are cardinally widened when compared to corresponding reflexes of graphitic carbon nitride [24] and graphite powder, respectively. In the glassy carbon case, this widening is explained by most authors in terms of semi-cristallic or so called turbostratic structure of the latter: the material arrangement can be represented as ribbons or globules of ordered graphene-based phase immersed in amorphous carbon matrix.

If the same model is applicable to our novel polymer-derived carbon nitrides, the average size of ordered units in their structure can be calculated by fitting Voigt function and finally using Scherrer equation to obtain the sizes of crystallites (calculation details in the SI). From this approach, the following values of apparent crystallite sizes were obtained: $1.89 \mathrm{~nm}$ for poly(CYA-Cl-NH)-derived film, $1.44 \mathrm{~nm}$ for poly(CYA-Cl-AMTAZ)-derived film, $1.47 \mathrm{~nm}$ for poly(CYA-Cl-AMCARTRIA)-derived films, $0.89 \mathrm{~nm}$ for reference glassy carbon powder. Hence, although more precise experiments are required in order to elucidate the explicit structure of newly synthesized polymer-derived carbon nitride films, their X-ray diffraction patterns allow identifying them as semiamorphous materials with crystallite sites of the same order of magnitude as in glassy carbons. 
Table 3 Measured contact angles

\begin{tabular}{lll}
\hline Precursor polymer & Annealed in Ar, degrees & Annealed in air, degrees \\
\hline Poly(CYA-Cl-NH) & 76 & 31 \\
poly(CYA-Cl-AMTAZ) & 48 & $<20$ \\
poly(CYA-Cl-AMCARTRIA) & 51 & $<20$ \\
\hline
\end{tabular}

\section{Contact angle measurements}

Water wettability of coatings is of immense importance for all applications where films are brought in contact with water-based liquid. Contact angles have been measured by the static sessile drop method for films on Ti foil support, annealed in standard regime with $550{ }^{\circ} \mathrm{C}$ final temperature in $\mathrm{Ar}$ and air atmosphere.

Table 3 shows that air-annealed samples demonstrated much lower contact angles, presumably due to oxidative elimination of surface pollution by trace hydrophobic contaminants. In all measurement where contact angles below 20 degrees were recorded, drops have been slowly spreading on the film during the procedure, so the exact value has not been determined.

\section{Characterization of electrochemical properties of annealed films}

UV-VIS DRS measurements concede to characterize all films, annealed at $550{ }^{\circ} \mathrm{C}$, as low bandgap semiconductors (1.71-1.99 eV). The massive difference between these observed values with the bandgap value reported for graphitic carbon nitride, allows considering the newly synthesized coatings to be extrinsic semiconductors with bandgap reduced presumably by carbon doping.

In order to investigate electrochemical parameters of films in a way reflecting their potential practical application, all three solutions of precursor polymers were applied on carbon cloth (CC) electrodes, produced from Alfa Aesar $3.18 \mathrm{~mm}$ thick carbon cloth sheets. $3.18 \times 3.18 \times 50 \mathrm{~mm}$ electrodes were cut out of the cloth and half-dipped in a vial with as-synthesized solution of precursor polymers. The vial with electrode vas sonicated for 1-2 min to ensure complete wetting of the dipped part, then electrode fixed with coated end downwards in a vacuum chamber and dried in $0.3 \mathrm{~Pa}$ vacuum for $12 \mathrm{~h}$, then in air at $110{ }^{\circ} \mathrm{C}$ for $24 \mathrm{~h}$. The treated electrodes were annealed at $550{ }^{\circ} \mathrm{C}$ in Ar flow according to the standard heating regime. A control uncoated CC electrode of the same dimensions was annealed in the same conditions.

Electric impedance measurements were carried out by means of EIS spectroscopy. $0.01 \mathrm{~N} \mathrm{Fe}(\mathrm{CN})_{6}{ }^{3-}$ / $0.01 \mathrm{~N} \mathrm{Fe}(\mathrm{CN})_{6}{ }^{4-} / 0.1 \mathrm{~N} \mathrm{KCl}$ solution was chosen as redox-buffered electrolyte. Annealed bare $\mathrm{CC}$ and film-coated CC electrodes were immersed into solution by $5 \mathrm{~mm}$, forming solid-liquid geometric interface surface of approximately $0.7 \mathrm{~cm}^{2}$ and immersed electrode volume of about $0.05 \mathrm{~cm}^{3}, 6 \mathrm{~cm}^{2} \mathrm{Pt}$ mesh has been used as a counter-electrode in all electrochemical experiments. The following EIS experiment parameters were chosen: frequency range from $0.1 \mathrm{~Hz}$ to $100,000 \mathrm{~Hz}, 10$ points/decade, sinus amplitude $10 \mathrm{mV}$, direct current (DC) potential $0 \mathrm{mV}$ versus $\mathrm{Ag} / \mathrm{AgCl} /$ saturated $\mathrm{KCl}$.

As can be seen from Fig. 10, almost perfect fitting of the experimental data with the corresponding simple equivalent circuit was achieved. The best-fitting circuit is represented by a capacitor and a
Figure 10 Fitted Niquist plot for poly(CYA-Cl-AMTAZ)derived coating.

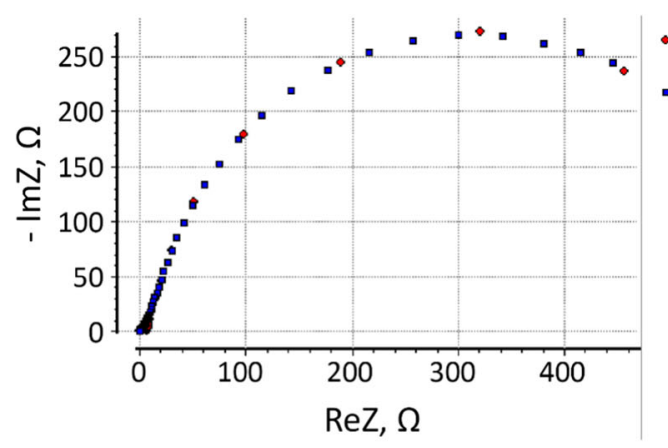

- Niquist plot from the experimental data - Niquist plot simulated in EIS Spectrum Analyser

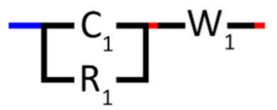

Equivalent circuit used for the simulation:

$C_{1}=0.165 F R_{1}=400 \Omega W_{1}=8.2 \Omega \mathrm{s}^{-1 / 2}$ 
resistor connected in parallel together with a serially connected Warburg element.

A control EIS experiment carried out with an uncoated electrode afforded a spectra that was ideally fitted by the same equivalent circuit, with capacitance and resistance of $0.008 \mathrm{~F}$ and $13 \mathrm{k} \Omega$, respectively, and Warburg impedance of $270 \Omega \mathrm{s}^{-1 / 2}$.

The aerial capacitance of untreated carbon cloth is reported by Yi-Jie Gu et al. [25] and Dong Ye et al. [26] to be 0.96 and $0.8-0.9 \mathrm{mF} \mathrm{cm}^{-2}$, respectively. Both works report treated CC (calcined in air and electrochemically oxidized/reduced, respectively) to have largely higher aerial capacitances with respective maximum values 1136.7 and $505.5 \mathrm{mF} \mathrm{cm}{ }^{-2}$.

The measured aerial capacitance of annealed carbon cloth (0.008 $\mathrm{F}$ per $0.7 \mathrm{~cm}^{2}$ of projected area), or $11.4 \mathrm{mF} \mathrm{cm}^{-2}$ can hence be classified as rather low, being only one order of magnitude larger than untreated CC aerial capacitance reported. At the same time, the aerial capacitance of coated electrodes $\left(236 \mathrm{mF} \mathrm{cm}^{-2}\right)$ is comparable with the reported CCbased modified electrodes proposed for super capacitor applications.

The resistance measured for both coated and uncoated CC electrodes, corresponding to the semicircle diameter on the Niquist plots, coincides with the interfacial resistance, while the internal resistance of both cells, given by the high-frequency $Z^{\prime}$ value, was in the range of several Ohms. The impedancefrequency behavior of both cells allows assuming their impedance as classically faradaic, with double layer capacitance and redox process-mediated resistance standing for $C_{1}$ and $R_{1}$ values, respectively, and
Warburg impedance probably originating from diffusion kinetics. The effective resistivity on the solidelectrolyte junction of the coated electrodes can be calculated in the assumption of uniform $50 \mu \mathrm{m}$ coating to be $56 \mathrm{kOhm} \mathrm{cm}$ according to EIS, allowing to classify the coatings as conductive rather than semi conductive. Moreover, the intrinsic resistivity of films is most likely fairly lower, as the faradaic resistivity is affected by reaction transfer kinetics.

In order to further elucidate the efficiency of electron transfer through electrode-electrolyte interphase, cyclic voltammetry $(\mathrm{CV})$ curves of annealed bare CC/annealed poly(CYA-Cl-AMTAZ)-coated CC electrodes were recorded in the same $\mathrm{Fe}^{3+} / \mathrm{Fe}^{2+}$ electrolyte and in the same conditions. To reduce capacitive currents, all scans were operated at low scanning speed of $10 \mathrm{mV} / \mathrm{s}$. The results are provided in the Fig. 11.

Surprisingly, although in agreement with high faradaic resistances measured by EIS, annealed bare CC electrodes provided very low specific currents in both oxidation and reduction half-waves. In contrast, all coated CC electrodes developed pronounced halfwaves with maximum currents, exceeding 6-7 times the corresponding currents for both oxidation and reduction peaks on untreated CC electrodes.

In order to investigate the electrochemical activity and stability of coatings at high overpotentials in acidic aqueous media, $100 \mathrm{CV}$ scans in $1 \mathrm{~N}$ sulphuric acid in the potential range from $-1 \mathrm{~V}$ to $+1.5 \mathrm{~V}$ versus $\mathrm{Ag} / \mathrm{AgCl}$ at $10 \mathrm{mV} / \mathrm{s}$ were undertaken. Prior to scanning, the electrodes were conditioned for $10 \mathrm{~min}$
Figure $11 \mathrm{CV}$ scans of bare and coated $\mathrm{CC}$ in $0.01 \mathrm{~N}$ $\mathrm{Fe}(\mathrm{CN})_{6}{ }^{3-} / 0.01 \mathrm{~N} \mathrm{Fe}(\mathrm{CN})_{6}{ }^{4-}$ / $0.1 \mathrm{~N} \mathrm{KCl}$ solution.

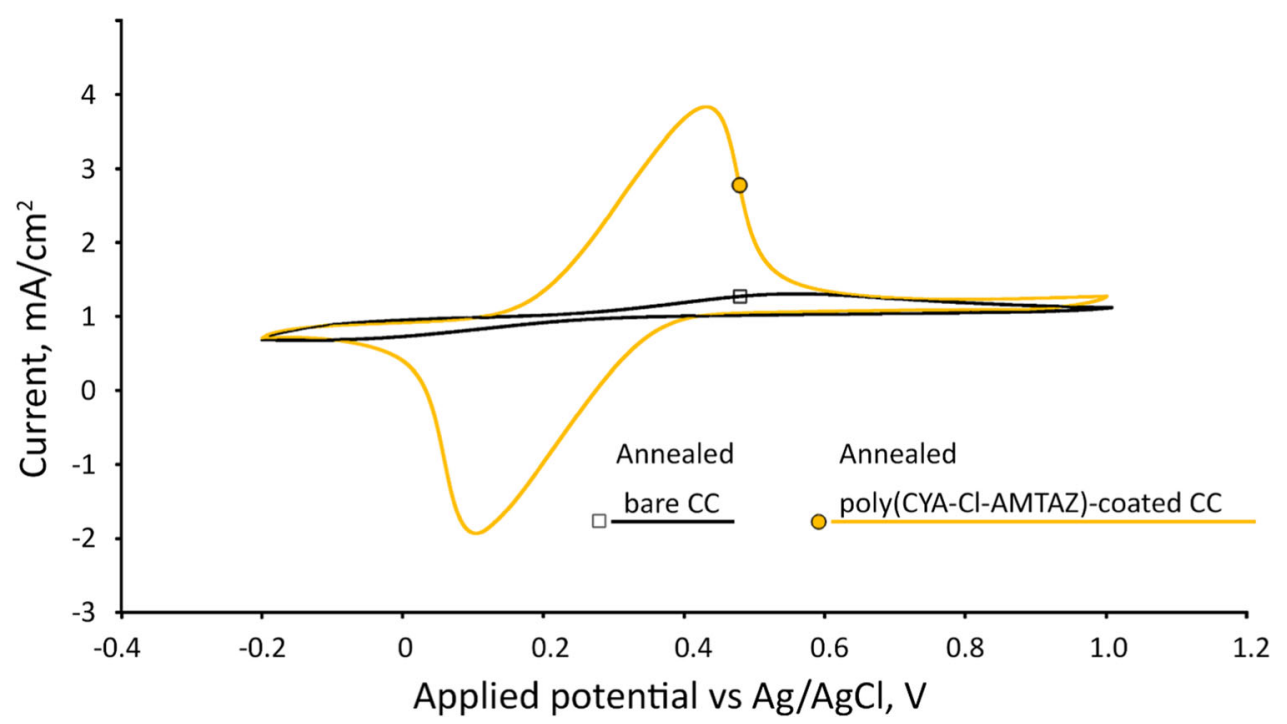


Figure 12 Voltammetric scans for CYA-Cl-AMTAZcoated electrodes in $1 \mathrm{~N}$ $\mathrm{H}_{2} \mathrm{SO}_{4}$.

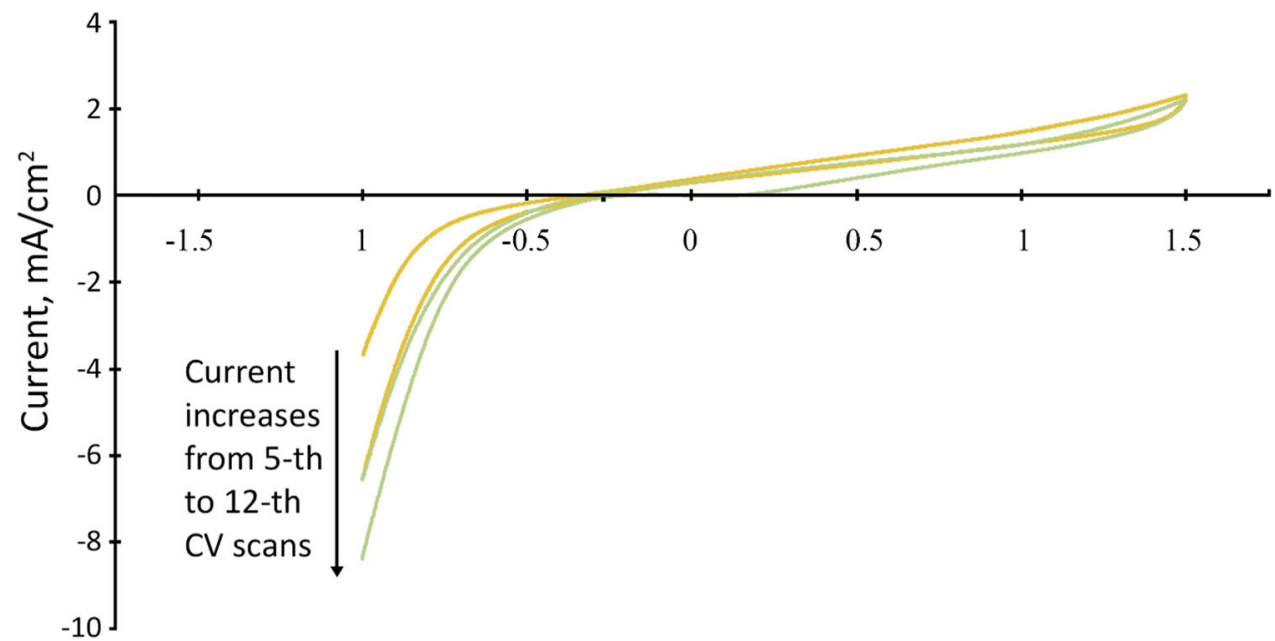

Potential vs $\mathrm{Ag} / \mathrm{AgCl}$

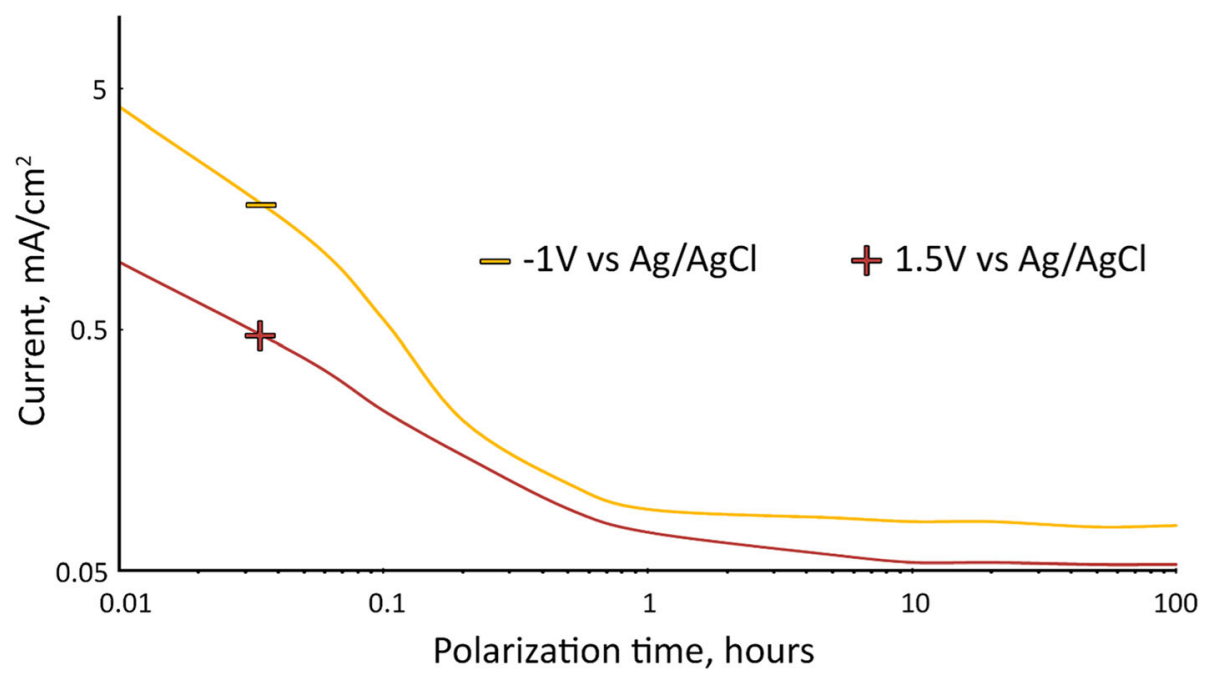

Figure 13 Chronoamerometric curves for poly(CYA-Cl-AMTAZ)/CC annealed at $550{ }^{\circ} \mathrm{C}$ at cathodic and anodic polarizations (current modules shown).

at +1 . $5 \mathrm{~V}$ versus $\mathrm{Ag} / \mathrm{AgCl}$ to eliminate possible surface contamination.

As can be seen from the Fig. 12, coated electrodes, after first several scans, demonstrate extremely stable electrochemical behavior. In the negative branch of the CV, currents increase progressively from 1st to 12th scans and stabilize during all the following CV passes with only negligible differences between 12 and 100th scans. Positive currents expose noticeable reproducibility with no apparent changes after first 3 scans. Surprisingly, voltamperograms in sulphuric acid demonstrate low capacitive currents, corresponding to only dozens of $\mu$ F-level capacitances.

The most intriguing, however, is the presence of noticeable and reproducible anodic current, appearing above $-0.25 \mathrm{~V}$ vs $\mathrm{Ag} / \mathrm{AgCl}$ and almost linearly increasing with potential.

Chronoamperometric characterization (Fig. 13) of electrodes provides furthermore support for the hypothesis of reversible oxidation and reduction of the surface, demonstrating quick current deterioration with time at applied static potential in both oxidation and reduction modes. 


\section{Results and discussion}

In this paper, we demonstrate a way to fabricate carbon nitride analogues of glassy carbons by means of pyrolysis of ultra nitrogen-rich polymeric precursors. The logics behind the selection of possible precursors has been based on an observation that nearly all the compounds, used as precursors for carbon nitride, do not contain $\mathrm{C}-\mathrm{C}$ bonds, being instead based on $\mathrm{C}-\mathrm{N}$ or $\mathrm{N}-\mathrm{N}$ sequences. It seemed reasonable to assume that this could be a critical factor affecting pyrolysis pathway and determining the kinetic selection mechanism for azagraphene/azinebased structure instead of graphene-derived structural motifs, represented in «classical» pyrolytic carbons.

Likewise, we wanted the precursor to be a polymer in order to render amorphous or semi-amorphous structure of the annealed material. In the seek for «C$\mathrm{C}$ free» polymers, we synthesized by means of classical polycondensation a linear imide of chlorotriazine (poly(CYA-Cl-NH) and two block-polymers based on triazine/tetrazole poly(CYA-Cl-AMTAZ) or carboxytriazole (poly(CYA-Cl-AMCARTRIA), respectively. The latter, although containing a $\mathrm{C}-\mathrm{C}$ bond, can be viewed a C-N polymer due to decarboxylation, presumable taking place before main pyrolysis steps.

All these polymers exhibit excellent solubility in aprotic solvents in the form of DIPEA salts, directly obtainable from syntheses.

According to the ${ }^{1} \mathrm{H}$ NMR spectra, poly(CYA-ClAMTAZ) exhibits strongly acidic imide protons and appears to exist in DMAc solution in the form of corresponding DIPEA salt with imide proton fully dissociated and showing up in the ${ }^{1} \mathrm{H}$ spectrum as DIPEA $\cdot \mathrm{H}^{+}$signal, while two other polymers are presumably characterized by low imide acidity.

From the SEC chromatography data it can be concluded that poly(CYA-Cl-NH) and poly(CYA-ClAMTAZ) are high molecular weight polymers with two maximums in the molecular mass distribution. The poly(CYA-Cl-AMCARTRIA), according to SEC results, should be considered as oligomer containing on average 2 triazine- $\mathrm{NH}$-carboxytriazole units. This presumption, however, goes in contradiction with the previously mentioned absence of any noticeable signals in the ${ }^{1} \mathrm{H}$ NMR spectra that could be related to the presence of amino or imino hydrogens of free triazine monomer or oligomers.
IR spectra of all the synthesized polymers reveal their structural similarity with "classical" carbon nitride structures as well as annealed films obtained therefrom, albeit with several specific absorption maximums. The spectrum of poly(CYA-Cl-AMTAZ) demonstrates a noticeable adsorption at $783 \mathrm{~cm}^{-1}$, which gradually fades upon annealing of the polymer and does not show up in the spectra of poly(CYA-Cl-NH) and poly(CYA-Cl-AMCARTRIA) or annealed films obtained from these polymers. According to the IR spectra of substituted 1,2,3,4-tetrazoles, published in the literature, this signal can be viewed as characteristic for tetrazole systems. For instance, it appears at $790.47 \mathrm{~cm}^{-1}$ for 5-phenyl-1Htetrazole, at $791.77 \mathrm{~cm}^{-1}$ for 5-(4-hydroxyphenyl)-1Htetrazole, at $778.32 \mathrm{~cm}^{-1}$ for 1-(3-bromophenyl - $1 \mathrm{H}$ tetrazole [27].

Accordingly, almost complete disappearance of this peak at $550{ }^{\circ} \mathrm{C}$ for poly(CYA-Cl-AMTAZ) can be attributed to full decomposition of tetrazole precursor at this temperature - a surprisingly high thermal stability for tetrazoles, especially in comparison with the monomeric 5-aminoterazole [16].

The intensive asymmetric shoulder placed between 1270 and $1400 \mathrm{~cm}^{-1}$ for poly(CYA-Cl-NH) and $1200-1500 \mathrm{~cm}^{-1}$ for other two polymers is essential for understanding the spectra.

In the family of films derived from poly(CYA-Cl$\mathrm{NH}$ ), two maximums of this peak are originally observed at 1295 and $1320 \mathrm{~cm}^{-1}$ and, upon heating, decrease and move towards steadily to produce one bell-shaped maximum at $1330 \mathrm{~cm}^{-1}$ for the film, annealed at $550{ }^{\circ} \mathrm{C}$. In the case of poly(CYA-ClAMTAZ), this band shows up at $1402 \mathrm{~cm}^{-1}$ for the source polymer and, upon annealing, quickly decreases in intensity and moves to higher wavenumbers to finally disappear at $550{ }^{\circ} \mathrm{C}$.

Spectra of poly(CYA-Cl-AMCARTRIA) films exhibit widened peaks with few characteristic features. Expectably, non-annealed film demonstrates $\mathrm{C}=\mathrm{O}$ vibration at $1707 \mathrm{~cm}^{-1}$, disappearing already when pyrolized at $350{ }^{\circ} \mathrm{C}$. A small peak at $2985 \mathrm{~cm}^{-1}$, corresponding presumably to $-\mathrm{OH}$ vibrations of $-\mathrm{COOH}$ groups, fades at pyrolysis above $350{ }^{\circ} \mathrm{C}$. Thus, FTIR data for poly(CYA-Cl-AMCARTRIA) support the presumption that this polymer easily decarboxylates in relatively mild heating conditions.

With the goal to assign the spectral features appearing in the spectra of carbon nitride $(\mathrm{CNx})$ films, we compared the spectra of films, measured in 
this work, with published FTIR data on monomeric triamino s-triazine (melamine) and triamino tri-sheptazine (melem) along with spectra of other materials of carbon nitride family, believed to consist of triazine, heptazine or mixed structural motifs.

The work on vibrational-mode assignment for IR spectra of crystalline and gas phase melamine performed by Yuan et al. [28] reasserts the assignments reported by other authors, for instance referring the vibrations at 1424 and $1577 \mathrm{~cm}^{-1}$ with the $\mathrm{HCN}$ and $\mathrm{NH}_{2}$ bending coupled with ring deformation and $\mathrm{CN}$ stretching or $\mathrm{CN}$ stretching and $\mathrm{NH}_{2}$ bending, respectively.

This finding supports the hypothesis that the shoulder showing up between 1270 and $1400 \mathrm{~cm}^{-1}$ and gradually disappearing when annealing temperature increases, can be related to free $-\mathrm{NH}_{2}$ and other $\mathrm{H}$-containing functionalities, depleting with heating.

Comparison of melamine spectrum with IR spectra of monomeric alkylamides of heptazine, published by Zambon et al. [29], along with IR characterization of melem, performed by Jürgens et al. [19], allows to outline the same pattern in all studied spectra of monomeric compounds: appearance of two intensive absorption maximums in the proximity of $1430 \mathrm{~cm}^{-1}$ and $1530-1600 \mathrm{~cm}^{-1}$, respectively, with a pronounced low absorption region between them.

Notably, four polymeric $\mathrm{CN}_{\mathrm{x}}$ materials synthesized by means of solution-based reactions of cyanuric chloride with nitrogen sources, reported in the literature $([5,14,17,22])$, demonstrate the same tendency to possess an absorption gap between two intensive peaks in the area. On the other hand, the spectrum of G- $\mathrm{C}_{3} \mathrm{~N}_{4}$ presented by Li et al. [18], along with spectra of melon [4] and other $\mathrm{CNx}$ polymers reported to be based at least partially on heptazinic structural units $([17,30])$, exhibit multiple peaks or continuously filled absorption band in the range from $1430 \mathrm{~cm}^{-1}$ to $1530-1600 \mathrm{~cm}^{-1}$.

It should be noted that previous studies on interpretation of IR spectra of amorphous $\mathrm{CNx}$ films, performed by Ferrari et al. [31], led them to conclude that the entire region between 1000 and $2000 \mathrm{~cm}^{-1}$ should only be assigned to skeletal vibrations due to insensitivity of local maximums in this region to deuteration of film.

However, considering intensive absorption in this range demonstrated for monomeric triazines and heptazines, it remains contentious if these conclusions are applicable to azine-based polymers. Nevertheless, taking into account the fact that monomeric heptazines do not show any characteristic absorption nearby $1430 \mathrm{~cm}^{-1}$ but all heptazine- containing polymers exhibit characteristic absorption in this area, we suppose that this maximum is related to vibrations of $\pi$-delocalized polymeric system based on heptazinic framework-purely skeletal or combined with bending of substituting groups.

Another curious observation relates to the notable sharp peak always appearing in FTIR spectra of both triazine and heptazine-based materials at around $800 \mathrm{~cm}^{-1}$, assigned by Yuan et al. [28] to ring out-of-plane deformation $\left(808 \mathrm{~cm}^{-1}\right)$. According to our examination, in all spectra of triazine-based materials, hitherto reviewed as presenting an absorption gap in between 1430 and $1530 \mathrm{~cm}^{-1}$ and described in their research as triazine-based, this sharp peak appears in the range from 808 to $820 \mathrm{~cm}^{-1}$. In the materials believed to be based on heptzinic framework, this peak shows up in the $780-802 \mathrm{~cm}^{-1}$ region.

Hence, although the difference in the position of this vibration is small, it might be helpful in distinguishing between triazine- and heptazine-based structures. Interestingly, all reported amorphous carbon nitride films, obtained by means of reactive sputtering, do not demonstrate this signal in their IR spectra. This may be an additional indication in favor of the viewpoint that these materials do not contain imide bringing nitrogen and rather represent graphite-like structures with partial substitution of carbon by nitrogen.

DMAc solutions of all three polymers can easily be applied on different solid supports by most of conventional coating methods and make well-adhered films upon evaporation of the solvent. Presumably, DIPEA plays a critical role, rendering solubility of all the synthesized precursors by forming their salts, as it was demonstrated by NMR spectroscopy. Simultaneously, difficulties with DIPEA removal during films drying prior to their pyrolysis, confirmed by FTIR, results in inevitable doping of the resulting coatings with carbon, arising greatly reduced optical bandgaps and relatively high conductivity.

The hypothesis of significant doping by carbon of the resulting coatings was further supported by the elemental analysis data. Although the content of nitrogen in the annealed films is extremely high for the scale of nitrogen-rich carbons, it is significantly 
lower than the content of nitrogen in "classical" nitrides of carbon. Low bandgaps, obtained by Tauc plots fitting, also go in line with the hypothesis of highly doped semiconducting material.

XRD and microscopic characterization data both allow to consider the annealed films as semi-amorphous materials, smooth down to the level of dozens of nanometers. Although some signs of existence of nanometer-sized structural units have been observed, the evidences collected during the present study does not allow to characterize this structure.

Measured electrochemical characteristics of the annealed films undoubtedly make them engaging coatings for applications, involving the requirements of high capacitance, low resistance and high electrochemical stability. Although the elucidation of supercapacitive properties of the coated carbons was not in the focus of the current study, the obtained capacitance value of $236 \mathrm{mF} \mathrm{cm}{ }^{-2}$ allows to propose the newly synthesized coatings for further capacitorsrelated studies.

The most remarkable finding, however, is the combination of outstanding long-term electrochemical stability with high and reproducible anodic currents.

For graphitic carbon, the phenomenon of relatively high currents at positive polarizations well below the OER onset potentials is well described in the literature. For instance, Yi et al. [32] relates this observation to electrochemically active surface groups, assuming formation of surface oxides in the course of surface oxidation with oxidation/reduction peak maximums at $0.6 \mathrm{~V}$ and $0.5 \mathrm{~V}$ versus RHE, respectively. This and other previous works even describe peeling off the formed oxidized carbon layer in the form of nanoflakes or soluble polycyclic compounds, resulting in yellow-brown color change of electrolyte easily observable with polarization time. In contrast, no changes of electrolyte color during long-term polarization of carbon nitride-coated electrodes was observed even after tens of hours of polarization at potentials exceeding $1.5 \mathrm{~V}$ versus $\mathrm{Ag} / \mathrm{AgCl}$.

Our explanation of these observations includes reversible formation of carbon nitride oxide on the surface of the electrodes. Although further research is required to elucidate the precise surface chemistry of new electrode materials, it seems reasonable to assume that oxidized surface layers, in contrast with surface oxides formed on glassy carbon, are not detached from electrodes surface into electrolyte and undergo further reduction at negative scanning potentials. Thus, the negative current appearing below $-0.3 \mathrm{~V}$ may at least partially correspond to surface groups reduction and not HER. Visual absence of any signs of hydrogen evolution even at negative currents as large as $8 \mathrm{~mA} / \mathrm{cm}^{2}$ further supports this hypothesis. The observed voltamperograms shapes without any conspicuous peaks can be explained in terms of high diversity of surface groups energy states and/or their kinetic availability, corresponding to a continuum of apparent redox potentials.

\section{Conclusions}

Three novel linear 1,3,5-triazineimides have been synthesized by self-condensation of 2-amino-4,6dichloro-1,3,5-triazine and condensation of cyanuric chloride with 5-aminoterazole or 3-amino-5-carboxytriazole, respectively.

All polymers exhibit excellent solubility in bipolar solvents in the form of the corresponding salts with N, N-diisopropylethylamine. Polymer solutions allow formation of well-adhered thin films on metallic, ceramic and carbonaceous surfaces by spincoating, dip-coating, spraying or other conventional coating techniques, followed by evaporation of the solvent.

Annealing of polymer films on different substrates at $350-550{ }^{\circ} \mathrm{C}$ leads to their transformation to smooth partially ordered hydrophilic carbon nitride coatings with approximately 31 to 45 at $\%$ of nitrogen and noticeable oxygen and chlorine content.

Combined FTIR, XRD, elemental analysis and EDX data have allowed us to conclude that annealed films represent the new member of the family of carbon nitrides, based on heptazine structural motifs, although with noticeable carbon and oxygen doping and semi-amorphous structure. The surface of annealed films is smooth down to the level of tens of nanometers, as demonstrated by STM. UV-VIS diffuse reflectance spectroscopy has allowed classifying the materials as low-bandgap semiconductors with bandgap presumably lowered due to carbon doping and negatively correlating with carbon content. The properties of annealed films have exhibited only tiny dependence on the type of precursor polymer used, being to a greater extent associated with annealing conditions. 
Electrochemical impedance spectroscopy of coatings reveals their effective resistivity in the range of tens $\mathrm{kOhm} \mathrm{cm}$, although the intrinsic resistivity value can be much lower. It allows classifying coatings as conductive rather than semiconductive and supports the hypothesis of carbon doping.

Our preliminary assessment of electrochemical stability of coatings, in strongly acidic environment, has demonstrated outstanding endurance even at high anodic and cathodic polarizations, combined with clear evidence of redox non-innocence of materials. We hypothesize formation of surface carbon nitride oxides at high positive potentials and their reversible reduction below $-0.3 \mathrm{~V} \mathrm{Ag} / \mathrm{AgCl}$.

In general, the newly synthesized coating materials exhibit the overall properties and electrochemical behavior allowing to characterize them as heptazinebased analogues of turbostratic carbons, although more research is required to elucidate their specific structural patterns. In contrast with glassy carbon, its novel heptazine-based analogs can easily be obtained as coatings and require notably modest annealing temperatures. This opens up the opportunity to create electrochemically active composites with catalytic complexes and nanoparticles with moderate thermal sensitivity. In addition, low contact angles of coatings result in hydrophilic surfaces, potentially giving way for wettable coatings with properties, attractive for fuel cell, sensors, supercapacitors, MEMS devices and membrane applications.

\section{Funding}

Open Access funding provided thanks to the CRUECSIC agreement with Springer Nature. This project has received funding from the European Union's Horizon 2020 research and innovation program under the Marie Skłodowska-Curie grant agreement No. 713679 and by the Universitat Rovira i Virgili (URV), contract 2017MFP-COFUND-18. Funding for this research was provided by Ministerio de Ciencia, Innovación y Universidades, the Agencia Estatal de Investigación (AEI) and the European Regional Development Fund (ERDF), project RTI2018-096467$\mathrm{B}-\mathrm{I} 00$. The authors research group is recognized by the Comissionat per a Universitats i Recerca, DIUE de la Generalitat de Catalunya (2017 SGR 396), and supported by the Universitat Rovira i Virgili
(2019PFR-URV-33). This paper has been possible with the support of the Universitat Rovira i Virgili (URV) and Banco Santander.

\section{Declarations}

Conflict of interests All authors declare that they have no significant competing financial, professional, or personal interests that might have influenced the performance or presentation of the work described in this manuscript.

Open Access This article is licensed under a Creative Commons Attribution 4.0 International License, which permits use, sharing, adaptation, distribution and reproduction in any medium or format, as long as you give appropriate credit to the original author(s) and the source, provide a link to the Creative Commons licence, and indicate if changes were made. The images or other third party material in this article are included in the article's Creative Commons licence, unless indicated otherwise in a credit line to the material. If material is not included in the article's Creative Commons licence and your intended use is not permitted by statutory regulation or exceeds the permitted use, you will need to obtain permission directly from the copyright holder. To view a copy of this licence, visit http://creativecommons.org/licen ses $/$ by $/ 4.0 /$.

Supplementary Information: The online version contains supplementary material available at http s://doi.org/10.1007/s10853-022-06906-5.

\section{References}

[1] Schwarzer A, Saplinova T, Kroke E (2013) Tri-s-triazines (sheptazines) - From a «mystery molecule» to industrially relevant carbon nitride materials. Coord Chem Rev 257(13-14):2032-2062

[2] Heymann L, Schiller B, Noei H, Stierle A, Klinke C (2018) A New Synthesis approach for carbon nitrides: poly(triazine imide) and Its photocatalytic properties. ACS Omega 3(4):3892-3900

[3] Algara-Siller G, Severin N, Chong SY, Björkman T, Palgrave RG, Laybourn A et al (2014) Triazine-based graphitic carbon nitride: a two-dimensional semiconductor. Angew Chem Int Ed 53(29):7450-7455 
[4] Dong G, Zhang Y, Pan Q, Qiu J (2014) A fantastic graphitic carbon nitride $\left(\mathrm{g}-\mathrm{C}_{3} \mathrm{~N}_{4}\right)$ material: electronic structure, photocatalytic and photoelectronic properties. J Photochem Photobiol, C 20:33-50

[5] Xu J, Brenner TJK, Chabanne L, Neher D, Antonietti M, Shalom M (2014) Liquid-based growth of polymeric carbon nitride layers and their use in a mesostructured polymer solar cell with Voc exceeding 1 V. J Am Chem Soc 136(39):13486-13489

[6] Zhao J, Ma L, Wang H, Zhao Y, Zhang J, Hu S (2015) Novel band gap-tunable $\mathrm{K}-\mathrm{Na}$ co-doped graphitic carbon nitride prepared by molten salt method. Appl Surf Sci 332:625-630

[7] Zhou ZB, Cui RQ, Pang QJ, Hadi GM, Ding ZM, Li WY (2002) Schottky solar cells with amorphous carbon nitride thin films prepared by ion beam sputtering technique. Sol Energy Mater Sol Cells 70:487-493

[8] Urakami N, Kosaka M, Hashimoto Y (2019) Thermal chemical vapor deposition and luminescence property of graphitic carbon nitride film for carbon-based semiconductor systems. Jpn J Appl Phys 58(1):010907

[9] She X, Xu H, Xu Y, Yan J, Xia J, Xu L et al (2014) Exfoliated graphene- like carbon nitride in organic solvents: enhanced photocatalytic activity and highly selective and sensitive sensor for the detection of trace amounts of $\mathrm{Cu} 2+$. J Mater Chem A 2:2563-2570

[10] Yang S, Gong Y, Zhang J, Zhan L, Ma L, Fang Z et al (2013) Exfoliated graphitic carbon nitride nanosheets as efficient catalysts for hydrogen evolution under visible light. Adv Mater 25(17):2452-2456

[11] Kim OH, Cho YH, Chung DY, Kim MJ, Yoo JM, Park JE et al (2015) Facile and gram-scale synthesis of metal-free catalysts: toward realistic applications for fuel cells. Sci Rep 5:8376-8376

[12] Chekanova VD, Fialkov AS (1971) Vitreous carbon (preparation, properties, and applications). Russ Chem Rev 40:413

[13] Sharma S (2018) Glassy carbon: a promising material for micro- and nanomanufacturing. Materials 11(10):1857

[14] Cong K, Radtke M, Stumpf S, Schröter B, McMillan DGG, Rettenmayr M et al (2015) Electrochemical stability of the polymer-derived nitrogen-doped carbon: an elusive goal? Mater Renewable Sustain Energy 4(2):5

[15] Baliani A, Peal V, Gros L, Brun R, Kaiser M, Barrett MP et al (2009) Novel functionalized melamine-based nitroheterocycles: synthesis and activity against trypanosomatid parasites. Org Biomol Chem 7(6):1154

[16] Paletsky AA, Budachev NV, Korobeinichev OP (2009) Mechanism and kinetics of the thermal decomposition of 5-aminotetrazole. Kinet Catal 50(5):627-635
[17] Gu Q, Jia Q, Zhang S, Gao Z, Yang P (2019) In-situ growth of triazine-heptazine based carbon nitride film for efficient (photo)electrochemical performance. Catal Sci Technol 9:425-435

[18] Li X, Zhang J, Shen L et al (2009) Preparation and characterization of graphitic carbon nitride through pyrolysis of melamine. Appl Phys A 94:387-392

[19] Jürgens B (2003) 8-Triamino-tri-s-triazine, an important intermediate during condensation of melamine rings to graphitic carbon nitride: synthesis, structure determination by X-ray powder diffractometry, solid-state NMR, and theoretical studies. J Am Chem Soc 5(2):10288-10300

[20] Shi K, Shiu K-K (2002) Scanning tunneling microscopic and voltammetric studies of the surface structures of an electrochemically activated glassy carbon electrode. Anal Chem 74:879-885

[21] McDermott MT, McDermott CA, McCreery RL (1993) Scanning tunneling microscopy of carbon surfaces: relationships between electrode kinetics, capacitance, and morphology for glassy carbon electrodes. Anal Chem 6:937-944

[22] Chaudhary M, Nayak A, Muhammad R, Pradhan D, Mohanty P (2018) Nitrogen-enriched nanoporous polytriazine for high-performance supercapacitor application. ACS Sustain Chem Eng 6(5):5895-5902

[23] Bukalov SS, Zubavichus YV, Leites L, Sorokin AI, Kotosonov AS (2014) Structural changes in industrial glassy carbon as a function of heat treatment temperature according to Raman spectroscopy and X-Ray diffraction data. Nanosyst Phys Chem Math 5:186-191

[24] Fina F, Callear SK, Carins GM, Irvine JTS (2015) Structural investigation of graphitic carbon nitride via XRD and neutron diffraction. Chem Mater 27(7):2612-2618

[25] Gu YJ, Wen W, Wu JM (2018) Simple air calcination affords commercial carbon cloth with high areal specific capacitance for symmetrical supercapacitors. J Mater Chem A 6:21078-21086

[26] Ye D, Tang J, Wu Y (2016) Electrochemical activation of Carbon Cloth in aqueous inorganic salts solution for superior capacitive performance. Nanoscale 8:10406-10414

[27] Zamani L, Mirjalili BBF, Zomorodian K, Zomorodian S (2015) Synthesis and characterization of 5-substituted $1 \mathrm{H}$ tetrazoles in the presence of nano- $\mathrm{TiCl}_{4} \cdot \mathrm{SiO}_{2}$. S Afr J Chem 68:133-137

[28] Yuan X (2016) Combinatorial vibration-mode assignment for the ftir spectrum of crystalline melamine: a strategic approach toward theoretical ir vibrational calculations of triazine-based compounds. J Phys Chem A 120:7427-7433

[29] Zambon A (2016) s-Heptazine oligomers: promising structural models for graphitic carbon nitride. Chem Sci $7: 945-950$ 
[30] Lin Z, Lin L, Wang X (2015) Thermal nitridation of triazine motifs to heptazine-based carbon nitride frameworks for use in visible light photocatalysis. Chin J Catal 36(12):2089-2094

[31] Ferrari AC, Rodil SE, Robertson J (2003) Interpretation of infrared and Raman spectra of amorphous carbon nitrides. Phys Rev B 67(15):155306
[32] Yi Y (2017) Electrochemical corrosion of a glassy carbon electrode. Catal Today 295:32-40

Publisher's Note Springer Nature remains neutral with regard to jurisdictional claims in published maps and institutional affiliations. 